\title{
State of Alaska's salmon and people: introduction to a special feature
}

\author{
Peter A. H. Westley ${ }^{1}, \underline{\text { Jessica C. Black }}^{2}, \underline{\text { Courtney Carothers }}^{1}$ and Danielle Ringer $^{1}$
}

Key Words: Climate change, data accessibility, equity, Indigenous knowledge, natural resource management, scarcity, well-being

\section{INTRODUCTION}

The connection between salmon and people in Alaska runs deep. Few, if any, species on Earth have more profoundly shaped human culture and well-being than wild Pacific salmon, and in recent times, few species have been the center of more conflict. Despite wide-ranging migratory life histories, salmon connects people to place by returning with high fidelity to the streams of their birth. Origin stories, oral histories, art, songs, and customs illustrate the deep-time ties between salmon and Indigenous Peoples. Recent archaeological studies have provided complementary and consistent evidence that Alaska Native societies were harvesting salmon at least 11,000 years ago (Halffman et al. 2015). In just a few generations following colonization by western settlers, the landscape of relationships between people and salmon in Alaska transformed dramatically. Dominant Indigenous worldviews of salmon as sentient relatives deserving of respect and stewardship was in many ways usurped by western views of salmon as an economic commodity. Complex systems of Indigenous management, governed on a commitment between Tribes and the Creator, were suppressed, often violently, and eventually made invisible in a new dominant paradigm from the burgeoning field of western natural resource management: maximum-sustained yield, recruits and spawners, and density-dependence. Although much has changed in a small period, the connection between Alaskans and salmon has remained constant, though sometimes strained, and ever important.

The contemporary connections between people and salmon in Alaska are on full display in any tourist gift shop or art gallery, where salmon apparel and products are fashionable and prized as iconic. Those fortunate to travel to Indigenous and rural areas of Alaska cannot help but see how time in villages operates on a clock dictated by the return of the salmon. For example, smokehouses populate family's yards, beautiful, preserved salmon jars fill pantries, and salmon is shared and enjoyed with guests as a way to meaningfully connect with one another and engage with the nourishment and bonds that salmon provide. The importance of salmon to people in Alaska is also obvious on the bookshelf, where recent titles such as Amy Gulick's The Salmon Way, written for a general audience, beautifully captures in photography and words the linkages of salmon to people. Alaska salmon are also well represented in the digital universe, with recent initiates such as The Salmon Project (https://salmonproject.org/) and Salmon Life (https://salmonlife.org/) that capture the sublime power of story to connect Alaskans through salmon. Literature on the biology, ecology, and conservation of salmon from natural sciences perspectives abound, although much of this can be inaccessible to the public due to the highly specialized and technical nature of the written work and the frequent paywalls for access to scientific journal articles. Despite efforts, such as by Salmon Net (https://salmon-net.org/), to break down the barriers to access and to facilitate interpretability of science for all, the inequitable distribution and availability of information and data remain a challenge for salmon-connected people and communities. Moreover, to date there have not been statewide reports that integrate biophysical, cultural, health and well-being, economic, and governance dimensions of salmon systems in a holistic fashion. This gap has impeded collective conversations and decision-making regarding the current and future state of Alaska's salmon and salmon-dependent people. We briefly describe the objectives and primary take-away messages, revealed in published papers in domain-specific journals and in this special feature of Ecology and Society from a rare project that integrated knowledge across systems.

\section{PROJECT OBJECTIVES AND OUTCOMES}

The State of Alaska's Salmon and People (SASAP) https:// alaskasalmonandpeople.org/ project was launched in 2016 seeking to address knowledge gaps and data needs with a transformative approach. SASAP had several complementary goals: 1) To elevate the role of Indigenous knowledge and Alaska Native people in scientific processes and resource governance, 2) To increase discoverability and accessibility of salmon-related data, and 3) Synthesize current understandings of the complex salmon-people system in as holistic a manner as possible. The State of Alaska's Salmon and People was novel in scope by explicitly considering all regions of Alaska from deep time relationships before western contact to today and synthesized information not only on the salmon themselves, but on the close relationships between salmon and culture, health, and well-being, economic production, and governing systems. Over 125 participants contributed to SASAP, representing academia, agencies, businesses, non-profit organizations, and Tribes (https:// alaskasalmonandpeople.org/about/partners/). Structurally, SASAP was organized into working groups, supported by the National Center for Ecological Analysis and Synthesis (NCEAS) at the University of California Santa Barbara. In addition, a dedicated Data Task Force at NCEAS greatly facilitated the data needs of working group participants as well as squarely addressed SASAP's objective of data discoverability and accessibility more broadly.

As SASAP officially ended in 2019, it is possible to now reflect on the most salient outcomes of the work. First and foremost, the SASAP process has catalyzed interactions, strengthened relationships, and built a network of researchers and Indigenous knowledge bearers who are continuing the work in ongoing projects. For example, with funding from the National Science

${ }^{1}$ Department of Fisheries, University of Alaska Fairbanks, ${ }^{2}$ Department of Alaska Native Studies and Rural Development, University of Alaska Fairbanks 
Foundation (\#1936378) SASAP team members are working to Indigenize salmon science and management by equitably and respectfully including Indigenous people and knowledge systems in scientific and governance processes. The Indigenizing Salmon Science and Management project has built a broad network of Indigenous and allied researchers across Alaska, who work collectively to address three, broad questions: 1) What are the Indigenous values, knowledge, management, and governance mechanisms that will improve the long-term sustainability and equity of the Alaska salmon system for the benefit of all? (2) What do we learn about the strengths and weaknesses of our current salmon management system when we view it from Indigenous experiences and perspectives? (3) How can Indigenous values, knowledge, and governance mechanisms be better included in current or alternative management systems?

Beyond research, the NSF Graduate Research Traineeship (\#2022190) Tamamta - meaning "All of Us" in the Sugpiaq and Yup'ik languages - was launched in 2021, with leadership, including the authors, whose relationships were galvanized through SASAP (https://www.tamamta.org). Holistic regionspecific overviews of the Alaska salmon-people system are freely available on the SASAP website (https://alaskasalmonandpeople. org/about/regions/), and results of technical papers are freely available in a variety of outlets, including open-access journal articles outside of this special feature. For example, results from SASAP working groups have contributed to a new understanding of the potential for ocean carrying capacity and changing physical and biological conditions, including intraspecific competition, across regions of the North Pacific Ocean and how they shape salmon survival (Connors et al. 2020). Consistent with widespread observations from local harvesters and Indigenous subsistence fishers, Oke et al. (2020) show that four species of salmon in Alaska are rapidly declining in size and that the most important drivers associated with the changes also appear to be occurring in the ocean. In addition, SASAP funding and leadership facilitated the thorough re-writing and updating, including a new accessible digital format, of the Alaska Department of Fish \& Game's widely circulated publication Alaska's Wild Salmon. Finally, the work of the Data Task Force of SASAP has resulted in the publishing of over 100 of the most important datasets related to the salmon-people system. These datasets are archived in perpetuity on the KNB database of NCEAS (https://knb.ecoinformatics.org/portals/SASAP/data). The importance of these datasets is evident by the thousands of individual downloads. For example, datasets on the earnings by permit holder residence status (https://doi.org/10.5063/ F1WW7FZ2) have garnered over 22,000 downloads and a summary of the historical salmon abundance by region (https:// doi.org/10.5063/QV3JZW) over 19,000 downloads. While far from perfect and already needing updating to the most current years of data, the existing SASAP datasets are a major step forward to leveling the playing field in terms of data accessibility and use (all are freely accessible at the link above).

The completion of this special feature in Ecology and Society will stand as another lasting outcome of SASAP. Papers in this feature weave strands of the complex and entwined salmon-people system: ranging from biophysical linkages that intersect with local decision making about land use patterns in a rapidly urbanizing region of Southcentral, Alaska (Walker et al. 2021), to a reframing of salmon sustainability through the framework of human wellbeing (Donkersloot et al. 2020), to a synthesis affirming the deeptime relationships between salmon and people and identifying the inequities that threaten those relationships (Carothers et al. 2021), to a framework for incorporating local Indigenous information into real-time salmon management decisions (Inman et al. 2021), and to a stark reminder that the savory taste of salmon can turn bitter through severed governance relationships between Indigenous peoples and state and federal management systems (Voinot-Baron 2020).

\section{KEY INSIGHTS FROM THE SPECIAL FEATURE}

We invite readers to engage with these papers and to struggle with uncomfortable truths. While we believe that the papers deserve to stand on their own and do not summarize them here, we do synthesize what we consider the most salient messages emerging from this collection. Sustainability depends on much more than simply protecting the abundance or productivity of salmon stocks. While necessary for sustainability, salmon abundance alone is insufficient to ensure the health of the relationships between salmon and people. The well-being of salmon-connected peoples is diminished not only in times of scarcity, but when barriers to access are implemented or criminalization of traditional and customary practices are institutionalized through governance systems and profit-driven natural resource management policies. As a result, work to achieve true sustainability of Alaska salmon and people necessitates an equally important focus on equity. Papers in this volume and the current and future work of many SASAP scientists shift away from a myopic focus on the fish themselves to more holistic views of strengthening and supporting the relationships between salmon, people, and place. Finally, the papers in this feature underscore that the gravity of the problems facing salmon and people in the $21^{\text {st }}$ century require the best available minds and knowledge - both western and Indigenous - if there is hope of meaningfully maintaining and strengthening the relationships that have persisted for millennia.

Responses to this article can be read online at: https://www.ecologyandsociety.org/issues/responses. php/12910

\section{Acknowledgments:}

The State of Alaska Salmon and People project was made possible by the heroic efforts of many people behind the scenes. In particular, we are indebted to Ian Dutton, Frank Davis, Matt Jones, Jeanette Clark, Jared Kibele, Ginger Gillquist, and all staff at NCEAS that made working groups function. We graciously acknowledge funding from the Gordon and Betty Moore Foundation and the vision of Erin Dovichin to bring this project to life. Finally, we want to acknowledge the Indigenous land and water on which this work was completed and honor the 10,000 plus years of ongoing stewardship. 


\section{LITERATURE CITED}

Carothers, C., J. Black, S. J. Langdon, R. Donkersloot, D. Ringer, J. Coleman, E. R. Gavenus, W. Justin, M. Williams, F. Christiansen, C. Stevens, B. Woods, S. Clark, P. M. Clay, L. Mack, J. Raymond-Yakoubian, A. Akall'eq Sanders, B. L. Stevens, and A. Whiting. 2021. Indigenous peoples and salmon stewardship: a critical relationship. Ecology and Society 26(1):16. https://doi. org/10.5751/ES-11972-260116

Connors, B., M. J. Malick, G. T. Ruggerone, P. Rand, M. Adkison, J. R. Irvine, R. Campbell, and K. Gorman. 2020. Climate and competition influence sockeye salmon population dynamics across the Northeast Pacific Ocean. Canadian Journal of Fisheries and Aquatic Sciences 77(6):943-9. https://doi. org/10.1139/cjfas-2019-0422

Donkersloot, R., J. C. Black, C. Carothers, D. Ringer, W. Justin, P. M. Clay, M. R. Poe, E. R. Gavenus, W. Voinot-Baron, C. Stevens, M. Williams, J. Raymond-Yakoubian, F. Christiansen, S. J. Breslow, S. J. Langdon, J. M. Coleman, and S. J. Clark. 2020. Assessing the sustainability and equity of Alaska salmon fisheries through a well-being framework. Ecology and Society 25(2):18. https://doi.org/10.5751/ES-11549-250218

Halffman, C. M., B. A. Potter, H. J. McKinney, B. P. Finney, A. T. Rodrigues, D. Y. Yang, and B. M. Kemp. 2015. Early human use of anadromous salmon in North America at 11,500 y ago. Proceedings of the National Academy of Sciences 112 (40):12344-8. https://doi.org/10.1073/pnas.1509747112

Inman, S. C., J. Esquible, M. L. Jones, W. R. Bechtol, and B. Connors. 2021. Opportunities and impediments for use of local data in the management of salmon fisheries. Ecology and Society 26(2):26. https://doi.org/10.5751/ES-12117-260226

Oke, K. B., C. J. Cunningham, P. A. H. Westley, M. L. Baskett, S. M. Carlson, J. Clark, A .P. Hendry, V. A. Karatayev, N. W. Kendall, J. Kibele, H. K. Kindsvater. 2020. Recent declines in salmon body size impact ecosystems and fisheries. Nature communications 11(1):1-3. https://doi.org/10.1038/s41467-020-17726$\underline{Z}$

Voinot-Baron, W. 2020. A bitter taste of fish: the temporality of salmon, settler colonialism, and the work of well-being in a Yupiaq fishing village. Ecology and Society 25(2):4. https://doi. org/10.5751/ES-11408-250204

Walker, C. M., D. F. Whigham, I. S. Bentz, J. M. Argueta, R. S. King, M. C. Rains, C. A. Simenstad, C. Guo, S. J. Baird, and C. J. Field. 2021. Linking landscape attributes to salmon and decision-making in the southern Kenai Lowlands, Alaska, USA. Ecology and Society 26(1):1. https://doi.org/10.5751/ES-11798-260101 